\title{
Low-dose morphine elicits ventilatory excitant and depressant responses in conscious rats: Role of peripheral $\mu$-opioid receptors ${ }^{*}$
}

\author{
Fraser Henderson Jr. ${ }^{1}$, Walter J. May ${ }^{1}$, Ryan B. Gruber ${ }^{2}$, Alex P. Young ${ }^{1}$, Lisa A. Palmer ${ }^{1}$, \\ Benjamin Gaston ${ }^{1}$, Stephen J. Lewis ${ }^{1,3 \#}$ \\ ${ }^{1}$ Pediatric Respiratory Medicine, University of Virginia School of Medicine, Charlottesville, USA \\ ${ }^{2}$ Division of Biology, Galleon Pharmaceuticals, Horsham, USA \\ ${ }^{3}$ Department of Pediatrics, Case Western Reserve University, Cleveland, USA \\ Email: "
}

Received 19 June 2013; revised 10 July 2013; accepted 21 July 2013

Copyright (C 2013 Fraser Henderson Jr. et al. This is an open access article distributed under the Creative Commons Attribution License, which permits unrestricted use, distribution, and reproduction in any medium, provided the original work is properly cited.

\begin{abstract}
The systemic administration of morphine affects ventilation via a mixture of central and peripheral actions. The aims of this study were to characterize the ventilatory responses elicited by a low dose of morphine in conscious rats; to determine whether tolerance develops to these responses; and to determine the potential roles of peripheral $\mu$-opioid receptors ( $\mu$-ORs) in these responses. Ventilatory parameters were monitored via unrestrained whole-body plethysmography. Conscious male Sprague-Dawley rats received an intravenous injection of vehicle or the peripherally-restricted $\mu$-OR antagonist, naloxone methiodide (NLXmi), and then three successive injections of morphine $(1 \mathrm{mg} / \mathrm{kg})$ given $30 \mathrm{~min}$ apart. The first injection of morphine in vehicle-treated rats elicited an array of ventilatory excitant (i.e., increases in frequency of breathing, minute volume, respiratory drive, peak inspiratory and expiratory flows, accompanied by decreases in inspiratory time and end inspiratory pause) and inhibitory (i.e., a decrease in tidal volume and an increase in expiratory time) responses. Subsequent injections of morphine elicited progressively and substantially smaller responses. The pattern of ventilatory responses elicited by the first injection of morphine was substantially affected by pretreatment with NLXmi whereas NLXmi minimally affected the development of tolerance to these responses. Low-dose morphine elicits an array of ventilatory excitant and depressant effects in conscious

*This work was supported by grants from Galleon Pharmaceuticals (S.J.L.).

Conflicts of Interest: None.

"Corresponding author.
\end{abstract}

rats that are subject to the development of tolerance. Many of these initial actions of morphine appear to involve activation of peripheral $\mu$-ORs whereas the development of tolerance to these responses does not.

Keywords: Morphine; Minute Ventilation; Tolerance; Peripheral and Central Opioid Receptors; Conscious Rats

\section{INTRODUCTION}

Morphine binds with relatively high affinity to $\mu$-opioid receptors ( $\mu$-ORs) and with lesser but relevant affinity to $\delta$-ORs and $\kappa$-ORs [1-5]. Analgesic doses of morphine depress ventilation in humans via central and peripheral effects [6,7]. These ventilatory depressant effects are due to activation of $\mu$-ORs although co-activation of $\delta$-or $\kappa$-ORs modulates these $\mu$-OR-mediated responses $[6,7]$. Studies in animals have demonstrated that opioids also depress ventilation via central and peripheral effects [see 8-10] including central [11] and vagal afferent-mediated [12] depression of ventilatory drive; skeletal muscle rigidity in the chest-wall [13]; and increases in pulmonary [14] and upper airway [15] resistances. Moreover, activation of central and peripheral $\mu$-ORs blunt the hypoxic ventilatory response [16], and opioids such morphine depress the responsiveness of carotid body chemoafferents to hypoxia and hypercapnia [17-19].

The ventilatory-depressant actions of morphine diminish upon repeated injection or continuous infusion in humans [20-22], pigs [23], rabbits [24], rats [25] and mice $[26,27]$ although there are reports that a loss of potency does not occur in humans [28], monkeys [29,30] or rats [31]. Nonetheless, it appears that a loss of the ventilatory-depressant actions of morphine develops more 
readily to higher doses of morphine (e.g., 5 - $10 \mathrm{mg} / \mathrm{kg}$, i.v.) and that this process has a temporal expression in that it takes at least 3 - 4 hours to develop [22,24]. If the above statements are correct, then the ventilatory depressant effects elicited by systemic injections of a lower dose of morphine should not result in tolerance, or if this tolerance were to develop, it would not be evident when repeat injections were given over a relatively short timespan. A confounding factor in designing low-dose studies is that lower doses of morphine [32,33], dermorphin [34] and fentanyl [35] can actually stimulate ventilation via activation of $\mu$-ORs. At present, the relative contributions of central and peripheral $\mu$-ORs to the expression of the ventilatory excitant effects of morphine have not been established.

The aims of this study were to 1 ) characterize the ventilatory effects elicited by three successive injections of a low dose of morphine $(1 \mathrm{mg} / \mathrm{kg}$, i.v. $)$ in conscious rats, 2) establish whether these responses are subject to tolerance, and 3) determine whether the responses elicited by morphine involve activation of peripheral $\mu$-ORs. The $1 \mathrm{mg} / \mathrm{kg}$ dose of morphine was selected because it elicits analgesia in rodents [36,37] and because of our preliminary evidence that this dose elicits a mixture of ventilatory excitant and depressant effects. The present study used naloxone methiodide (NLXmi), which is a relatively selective $\mu$-OR receptor antagonist [see 38,39], and which apparently does not cross the blood-brain barrier in rodents [40-43]. Evidence that peripheral ORs are involved in the effects of systemically-injected OR agonists was provided in studies in mice, which demonstrated that the analgesic and ventilatory depressant effects of morphine, methadone and heroin were reversed by NLXmi $[40,41]$.

\section{METHODS}

\subsection{Rats and Surgeries}

All studies were carried out in accordance with the National Institutes of Health Guide for the Care and Use of Laboratory Animals (NIH Publication No. 80-23) revised in 1996. The protocols were approved by the Animal Care and Use Committee of the University of Virginia. A total of 42 adult male Sprague-Dawley rats (Harlan, Madison, WI, USA) were implanted with jugular vein catheters under $2 \%$ isoflurane anesthesia. The rats were allowed 4 days to recover from surgery before use in the experiments. All catheters were flushed with phosphate-buffered saline (0.1 M, pH 7.4) at least $4 \mathrm{~h}$ before commencement of experiments. All of the studies were performed in a quiet laboratory with Relative $\mathrm{Hu}-$ midity of $52 \% \pm 2 \%$ and Room Temperature of $21.1^{\circ} \mathrm{C} \pm$ $0.2^{\circ} \mathrm{C}$.

\subsection{Ventilatory Parameters}

Ventilatory parameters were continuously recorded (i.e., breath by breath) in unrestrained rats by a whole-body plethysmography system (PLY 3223; BUXCO Incorporated, Wilmington, NC, USA), as described previously $[10,44]$. The parameters were 1$)$ frequency of breathing (Frequency), 2) tidal volume (TV), 3) minute volume (MV), 4) inspiratory time (Ti), 5) expiratory time (Ti), 6) peak inspiratory flow (PIF), 7) peak expiratory flow (PEF), and 8) the ratio of TV/Ti, an index of Respiratory Drive [45]. The provided software constantly corrected digitized values for changes in chamber temperature and humidity and a rejection algorithm was included in the breath-by-breath analysis to exclude nasal breathing. Due to the closeness of body weights in the two groups (see below), ventilatory parameters are presented without body weight corrections.

\subsection{Protocol}

The rats were placed in the plethysmography chambers and given 60 min to acclimatize before commencing the protocols. Study 1: One group of rats $(304 \pm 2 \mathrm{~g}, \mathrm{n}=9)$ received an injection of vehicle (saline, i.v.). Another group (300 $\pm 4 \mathrm{~g}, \mathrm{n}=9$ ) received NLXmi $(1.5 \mathrm{mg} / \mathrm{kg}$, i.v.). After $15 \mathrm{~min}$, all rats received an injection of morphine $(1 \mathrm{mg} / \mathrm{kg}$, i.v. $)$. After $30 \mathrm{~min}$, all rats received a second injection of morphine $(1 \mathrm{mg} / \mathrm{kg}$, i.v. $)$ and after 30 $\mathrm{min}$, a third injection of morphine $(1 \mathrm{mg} / \mathrm{kg}, i . v$. $)$. Study 2 : Two groups of rats ( $\mathrm{n}=6$ per group) underwent the exact same procedures as described above except that the dose of NLXmi used was $0.5 \mathrm{mg} / \mathrm{kg}$, i.v. Study 3: Two groups of rats ( $n=6$ per group) underwent the same procedures except that the dose of NLXmi used was $3 \mathrm{mg} / \mathrm{kg}$, i.v.

\subsection{Drugs}

Injectable (liquid) (+)-morphine sulfate $(10 \mathrm{mg} / \mathrm{ml})$ was from Baxter Healthcare Corporation (Deerfield, IL, USA). Naloxone methiodide powder was from Sigma (St. Louis, MO, USA).

\subsection{Statistics}

Recorded data (1 min bins) and derived parameters, Tidal Volume/Inspiratory Time and Response Area (cumulative arithmetic changes from pre-injection values) determined from the 1 min data bins, were taken for data analyses. The pre-drug 1 min bins excluded occasional marked deviations from resting ( $>3$ standard deviations) due to movements or scratching by the rats. This ensured accurate determinations of baseline parameters and calculations of changes elicited by the drugs. The data are presented as mean \pm SEM and were analyzed by one-way or two-way ANOVA followed by Student's modified $t$ test with Bonferroni corrections for multiple comparisons 
between means [46]. A value of $P<0.05$ denoted statistical significance.

\section{RESULTS}

\subsection{General Statement}

The following sections detail the results from Study 1, which used $1.5 \mathrm{mg} / \mathrm{kg}$ of NLXmi. The $0.5 \mathrm{mg} / \mathrm{kg}$ dose of NLXmi elicited substantially smaller inhibitory effects against the ventilatory actions of morphine than 1.5 $\mathrm{mg} / \mathrm{kg}$ of NLXmi whereas $3 \mathrm{mg} / \mathrm{kg}$ of NLXmi elicited virtually identical effects to those of $1.5 \mathrm{mg} / \mathrm{kg}$ (data not shown). As such, it is tentatively concluded that complete relatively blockade of peripheral $\mu$-ORs was achieved with the $1.5 \mathrm{mg} / \mathrm{kg}$ dose of NLXmi.

\subsection{Resting Ventilatory Parameters}

Resting ventilatory parameters recorded prior tothe injection of vehicle or NLXmi are summarized in Table 1. There were no between-group differences in any ventilatory parameter ( $P>0.05$, for all comparisons).

\subsection{Effects of Vehicle or and NLXmi on Baseline Parameters}

The injection of vehicle (saline) elicited minimal changes in ventilatory parameters (Figures 1-4). In contrast, NLXmi elicited transient changes in some parameters (values in parentheses reflect maximal changes) including increases in Frequency (+43 \pm 13 breaths/min, $P<$ $0.05)$, and $\mathrm{MV}(+47 \pm 16 \mathrm{mls} / \mathrm{min}, P<0.05)$, and decreases in Ti $(-0.4 \pm 0.1 \mathrm{sec}, P<0.05)$ and Te $(-0.7 \pm$ $0.2 \mathrm{sec}, P<0.05)$. All of the NLXmi-induced responses resolved before the first dose of morphine was given (Figures 1-4 and Table 1, column denoted Pre 1). It should be noted that there were no overt behaviors elicited by the injections of NLXmi (at any of the above doses).

\subsection{Effects of Morphine on Ventilatory Parameters in Vehicle or NLXmi-Treated Rats}

\subsubsection{Frequency}

Injection 1 of morphine (Inj-1m) in vehicle-treated (VEH) rats (see Figure 1) transiently decreased Frequency $(-13$ \pm 3 breaths/min). As seen in Figure 1 and Table 1 (see columns denoted "Max" for actual values), this drop in Frequency rapidly reversed to an increase $(+70 \pm 12$ breaths/min) that was sustained until Inj-2m was given (Table 2, column "Injection 2, pre”). Inj-2m in VEH rats elicited a transient decrease in Frequency $(-35 \pm 9$ breaths/min) whereas Inj-3melicited a minimal response (Table 1, columns denoted "Max" for actual values). As such, resting Frequency remained elevated after the first and each subsequent injection of morphine (Table 1, co- lumns denoted “pre”). Inj-1m in NLXmi-treated (NLXmi) rats (Figure 1) elicited an immediate increase in Frequency (+82 \pm 19 breaths/min)that was sustained until Inj-2m was given (Table 1, column denoted "Injection 2, pre”). Inj-2m elicited a transient fall in Frequency ( $-43 \pm$ 8 breaths/min) that was similar to that in VEH rats $(P<$ 0.05 ) whereas Inj-3m elicited minimal responses (Table 1, columns denoted “Max”). Inj-1m elicited a cumulative increase in Frequency in VEH rats (Table 2). Inj-2m elicited a minor cumulative decrease in Frequency whereas Inj-3m did not elicit a response. Inj-1m elicited a greater cumulative increase in Frequency in NLXmi rats than in VEH rats. Cumulative responses elicited by Injs-2m and $-3 m$ in NLXmi rats were equal to those in VEH rats.

\subsubsection{Tidal Volume}

Inj-1m in VEH rats (Figure $\mathbf{1}$ and Table 1) elicited a transient decrease in TV $(-0.8 \pm 0.2 \mathrm{mls})$ that resolved before Inj-2m was given. Injs-2m and -3m elicited smaller transient falls in TV $(-0.4 \pm 0.1$ and $-0.3 \pm 0.1 \mathrm{mls}$, respectively). Inj-1m in NLXmi rats (Figure 1, Table 1) elicited an immediate decrease in TV (unlike the delayed fall in VEH rats) of similar magnitude $(-0.5 \pm 0.1 \mathrm{mls}$, to that in VEH rats $(P<0.05)$. Injs-2m and $-3 \mathrm{~m}$ elicited similar responses $(-0.7 \pm 0.1$ and $-0.6 \pm 0.2 \mathrm{mls}$, respectively $(P<0.05)$ to those in VEH rats. Inj-1m elicited a cumulative decrease in TV in VEH rats. Injs-2m and -3m elicited smaller cumulative decreases (Table 2). Inj-1m elicited a smaller cumulative decrease in TV in NLXmi rats than in VEH rats (due to differences in resting values), whereas the cumulative responses elicited by Injs-2m and -3m were similar to those in VEH rats.

\subsubsection{Minute Volume}

Inj-1m in VEH rats (Figure $\mathbf{1}$ and Table 1) elicited a gradual increase in MV (+119 $\pm 24 \mathrm{mls} / \mathrm{min})$, which was sustained at the time-point (+30 min) when Inj-2m was given. In contrast, Injs-2m and $-3 m$ elicited transient falls in MV $(-125 \pm 26$ and $-71 \pm 10 \mathrm{mls} / \mathrm{min}$, respectively). As such, MV remained elevated after the first and subsequent injections of morphine. Inj-1m in NLXmi rats (Figure 1 and Table 1) elicited a gradual and sustained increase in MV (+161 $\pm 23 \mathrm{mls} / \mathrm{min})$, which was similar in magnitude to that in $\mathrm{VEH}$ rats $(P>0.05)$. Injs-2m and $-3 m$ elicited similar decreases to those in VEHrats $(-144$ \pm 27 and $-70 \pm 12 \mathrm{mls} / \mathrm{min}$, respectively). Inj-1m elicited a cumulative increase in MV in VEH rats (Table 2), whereas Injs-2m and -3m elicited cumulative decreases. Cumulative responses in NLXmi rats were similar to those in VEH rats.

\subsubsection{Inspiratory Time}

Inj-1m in VEH rats (Figure 2 and Table 1) elicited a 
Table 1. Ventilatory parameters during various stages of the experiment.

\begin{tabular}{|c|c|c|c|c|c|c|c|c|}
\hline \multirow[b]{2}{*}{ Parameter } & \multirow[b]{2}{*}{ Group } & \multirow[b]{2}{*}{ Pre } & \multicolumn{2}{|c|}{ Injection 1} & \multicolumn{2}{|c|}{ Injection 2} & \multicolumn{2}{|c|}{ Injection 3} \\
\hline & & & Pre 1 & Max & Pre 2 & Max & Pre 3 & Max \\
\hline \multirow[t]{2}{*}{ Frequency } & Vehicle & $108 \pm 8$ & $101 \pm 8$ & $178 \pm 14^{\dagger}$ & $172 \pm 21^{*}$ & $137 \pm 7^{\dagger}$ & $159 \pm 11^{*}$ & $140 \pm 14$ \\
\hline & NLXmi & $100 \pm 8$ & $102 \pm 9$ & $184 \pm 23^{\dagger}$ & $173 \pm 14^{*}$ & $130 \pm 9^{\dagger}$ & $155 \pm 10^{*}$ & $150 \pm 13$ \\
\hline \multirow[t]{2}{*}{ Tidal Volume } & Vehicle & $2.6 \pm 0.2$ & $2.7 \pm 0.2$ & $1.9 \pm 0.2^{\dagger}$ & $2.4 \pm 0.2$ & $2.0 \pm 0.1^{\dagger}$ & $2.4 \pm 0.1$ & $2.1 \pm 0.1^{\dagger}$ \\
\hline & NLXmi & $2.5 \pm 0.2$ & $2.4 \pm 0.2$ & $1.9 \pm 0.2^{\dagger}$ & $2.4 \pm 0.2$ & $1.7 \pm 0.1^{\dagger}$ & $2.6 \pm 0.2$ & $2.0 \pm 0.3^{\dagger}$ \\
\hline \multirow[t]{2}{*}{ Minute Volume } & Vehicle & $277 \pm 23$ & $290 \pm 29$ & $409 \pm 43^{\dagger}$ & $406 \pm 37^{*}$ & $281 \pm 13^{\dagger}$ & $374 \pm 19^{*}$ & $303 \pm 8^{\dagger}$ \\
\hline & NLXmi & $253 \pm 22$ & $273 \pm 22$ & $434 \pm 36^{\dagger}$ & $397 \pm 35^{*}$ & $253 \pm 9^{\dagger}$ & $382 \pm 22^{*}$ & $311 \pm 25^{\dagger}$ \\
\hline \multirow[t]{2}{*}{ Inspiratory Time } & Vehicle & $0.19 \pm 0.03$ & $0.23 \pm 0.03$ & $0.14 \pm 0.01^{\dagger}$ & $0.18 \pm 0.02$ & $0.14 \pm 0.01^{\dagger}$ & $0.19 \pm 0.02$ & $0.14 \pm 0.02^{\dagger}$ \\
\hline & NLXmi & $0.21 \pm 0.02$ & $0.21 \pm 0.02$ & $0.11 \pm 0.01^{\dagger}$ & $0.16 \pm 0.01^{*}$ & $0.11 \pm 0.01^{\dagger}$ & $0.18 \pm 0.02$ & $0.13 \pm 0.01^{\dagger}$ \\
\hline \multirow[t]{2}{*}{ Expiratory Time } & Vehicle & $0.36 \pm 0.05$ & $0.40 \pm 0.06$ & $0.22 \pm 0.02^{\dagger}$ & $0.23 \pm 0.02^{*}$ & $0.27 \pm 0.03$ & $0.22 \pm 0.02^{*}$ & $0.22 \pm 0.02$ \\
\hline & NLXmi & $0.39 \pm 0.03$ & $0.36 \pm 0.02$ & $0.24 \pm 0.03^{\dagger}$ & $0.26 \pm 0.02^{*}$ & $0.41 \pm 0.05^{\dagger \ddagger}$ & $0.25 \pm 0.02^{*}$ & $0.23 \pm 0.02$ \\
\hline \multirow[t]{2}{*}{ EIP } & Vehicle & $7.6 \pm 0.7$ & $7.4 \pm 0.3$ & $4.7 \pm 0.3^{\dagger}$ & $7.9 \pm 0.6$ & $5.4 \pm 0.2^{\dagger}$ & $8.9 \pm 0.9$ & $6.0 \pm 0.5^{\dagger}$ \\
\hline & NLXmi & $8.0 \pm 0.6$ & $8.3 \pm 0.4$ & $5.2 \pm 0.3^{\dagger}$ & $7.7 \pm 0.5$ & $4.9 \pm 0.2^{\dagger}$ & $8.2 \pm 0.5$ & $5.3 \pm 0.05^{\dagger}$ \\
\hline \multirow[t]{4}{*}{$\mathrm{TV} / \mathrm{Ti}$} & Vehicle & $14.1 \pm 1.7$ & $13.1 \pm 2.1$ & $21.8 \pm 1.9^{\dagger}$ & $15.3 \pm 1.6$ & $15.4 \pm 1.2^{\ddagger}$ & $13.8 \pm 0.8$ & $14.1 \pm 1.2^{\ddagger}$ \\
\hline & & & & $9.0 \pm 1.0^{\dagger}$ & & $10.6 \pm 0.6^{\dagger}$ & & $10.7 \pm 0.9^{\dagger}$ \\
\hline & NLXmi & $12.6 \pm 1.5$ & $11.2 \pm 1.3$ & $19.9 \pm 1.2^{\dagger}$ & $17.8 \pm 1.4^{*}$ & $23.6 \pm 1.5$ & $15.7 \pm 1.4^{*}$ & $18.0 \pm 1.0$ \\
\hline & & & & $10.9 \pm 1.1$ & & $9.7 \pm 0.3^{\dagger}$ & & $11.1 \pm 0.6^{\dagger}$ \\
\hline \multirow[t]{2}{*}{ PIF } & Vehicle & $21 \pm 3$ & $18 \pm 2$ & $46 \pm 3^{\dagger}$ & $23 \pm 3$ & $30 \pm 2^{\dagger}$ & $21 \pm 1$ & $24 \pm 2^{\dagger}$ \\
\hline & NLXmi & $19 \pm 2$ & $19 \pm 2$ & $45 \pm 4^{\dagger}$ & $27 \pm 2^{*}$ & $49 \pm 2^{\dagger \ddagger}$ & $24 \pm 2$ & $35 \pm 3^{\dagger \neq}$ \\
\hline \multirow[t]{2}{*}{ PEF } & Vehicle & $12 \pm 1$ & $12 \pm 1$ & $40 \pm 3^{\dagger}$ & $17 \pm 2^{*}$ & $26 \pm 2^{\dagger}$ & $16 \pm 1^{*}$ & $21 \pm 2^{\dagger}$ \\
\hline & NLXmi & $11 \pm 1$ & $12 \pm 1$ & $34 \pm 3^{\dagger}$ & $17 \pm 3^{*}$ & $37 \pm 3^{\dagger, \neq}$ & $17 \pm 2^{*}$ & $27 \pm 4^{\dagger}$ \\
\hline
\end{tabular}

Data are shown as mean \pm SEM. There were nine rats in each group. ${ }^{*} P<0.05$, significant change in baseline from Pre values. ${ }^{\dagger} P<0.05$, significant response; ${ }^{\ddagger} P<0.05$, NLXmi versus vehicle. Pre values represent parameters immediately before the injection of each dose of morphine (mean \pm SEM of the values recorded over the 5 min preceding each injection of morphine) and the maximum responses elicited by each dose of morphine are summarized in Table 1. The column denoted Pre 1 summarizes the mean \pm SEM of values recorded 11 - 15 min following injection of vehicle or NLXmi. The columns denoted Pre 2 and Pre 3 summarize the mean \pm SEM of values recorded 26 - 30 min following injection 1 and 2 of morphine (i.e., 5-0 min before injections 2 and 3 , respectively).

transient decrease in $\mathrm{Ti}(-0.9 \pm 0.2 \mathrm{sec})$ that resolved before Inj-2m was given. Injs-2m and $-3 m$ also elicited transient decrease sin $\mathrm{Ti}(-0.4 \pm 0.1$ and $-0.5 \pm 0.2 \mathrm{sec}$, respectively). Injs1-3m in NLXmi rats (Figure 2 and Table 1) also elicited decreases in $\mathrm{Ti}(-1.0 \pm 0.2,-0.5 \pm$ 0.1 , and $-0.5 \pm 0.1 \mathrm{sec}$, respectively) that were similar in magnitude to those in $\mathrm{VEH}$ rats $(P>0.05)$. As seen in Table 2, Inj-1m elicited similar cumulative decrease in $\mathrm{Ti}$ in VEH or NLXmi rats. Injs-2m and $-3 m$ did not elicit cumulative changes in $\mathrm{Ti}$ in VEH or NLXmi rats.

\subsubsection{Expiratory Time}

Inj-1m in VEH rats (Figure 2 and Table 1)elicited a transient increase in Te $(+0.22 \pm 0.04 \mathrm{sec})$ that reversed to a fall $(-0.14 \pm 0.02 \mathrm{sec})$, which was still present when Inj-2m was given. Injs-2m and $-3 m$ elicited negligible responses ( $-0.4 \pm 0.2$ and $0.0 \pm 0.2 \mathrm{sec}$, respectively). As such, Te remained decreased compared to pre-vehicle injection levels after each injection of morphine. Inj-1m in NLXmi rats (Figure 2 and Table 1) did not elicit the initial increase in Te $(+0.3 \pm 0.2 \mathrm{sec})$ as was observed in $\mathrm{VEH}$ rats. Instead, Te gradually fell $(-0.12 \pm 0.02 \mathrm{sec})$ to levels similar to those in VEH rats. Inj-2m in NLXmi rats elicited a transient increase in Te $(+0.15 \pm 0.04 \mathrm{sec})$ whereas Inj-3 elicited a negligible response. As seen in
Table 2, Inj-1m elicited a cumulative decrease in Te in $\mathrm{VEH}$ rats whereas Injs-2m and $-3 \mathrm{~m}$ elicited negligible responses. Inj-1m elicited a greater cumulative decrease in Te in NLXmi rats than in VEH rats. Injs-2m and -3m elicited negligible cumulative changes in NLXmi rats.

\subsubsection{End Inspiratory Pause}

Inj-1m in VEH rats (Figure 2 and Table 1) elicited a decrease in EIP $(-2.6 \pm 0.3 \mathrm{msec})$ that resolved by the time Inj-2m was administered. Injs-2m and $-3 m$ of morphine elicited similar peak decreases as elicited by inj-1 $(-2.5 \pm 0.4$ and $-2.9 \pm 0.3 \mathrm{msec}$, respectively, $P<0.05)$ that resolved somewhat quicker than that of Inj-1m. Injs-2m and -3m in NLXmi rats (Figure 2 and Table 1) elicited decreases in EIP $(-2.5 \pm 0.4$ and $-2.9 \pm 0.3 \mathrm{msec}$, respectively) that were similar in magnitude to those in VEH rats $(P>0.05)$. As seen in Table 2 , Inj-1m elicited a cumulative decrease in EIP in VEHrats whereas Injs$2 m$ and $-3 m$ elicited smaller cumulative responses. The cumulative responses in NLXmi rats were similar to those inVEH rats.

\subsubsection{Respiratory Drive (TV/Ti)}

Inj-1m in VEH rats (Figure 3 and Table 1) elicited a 

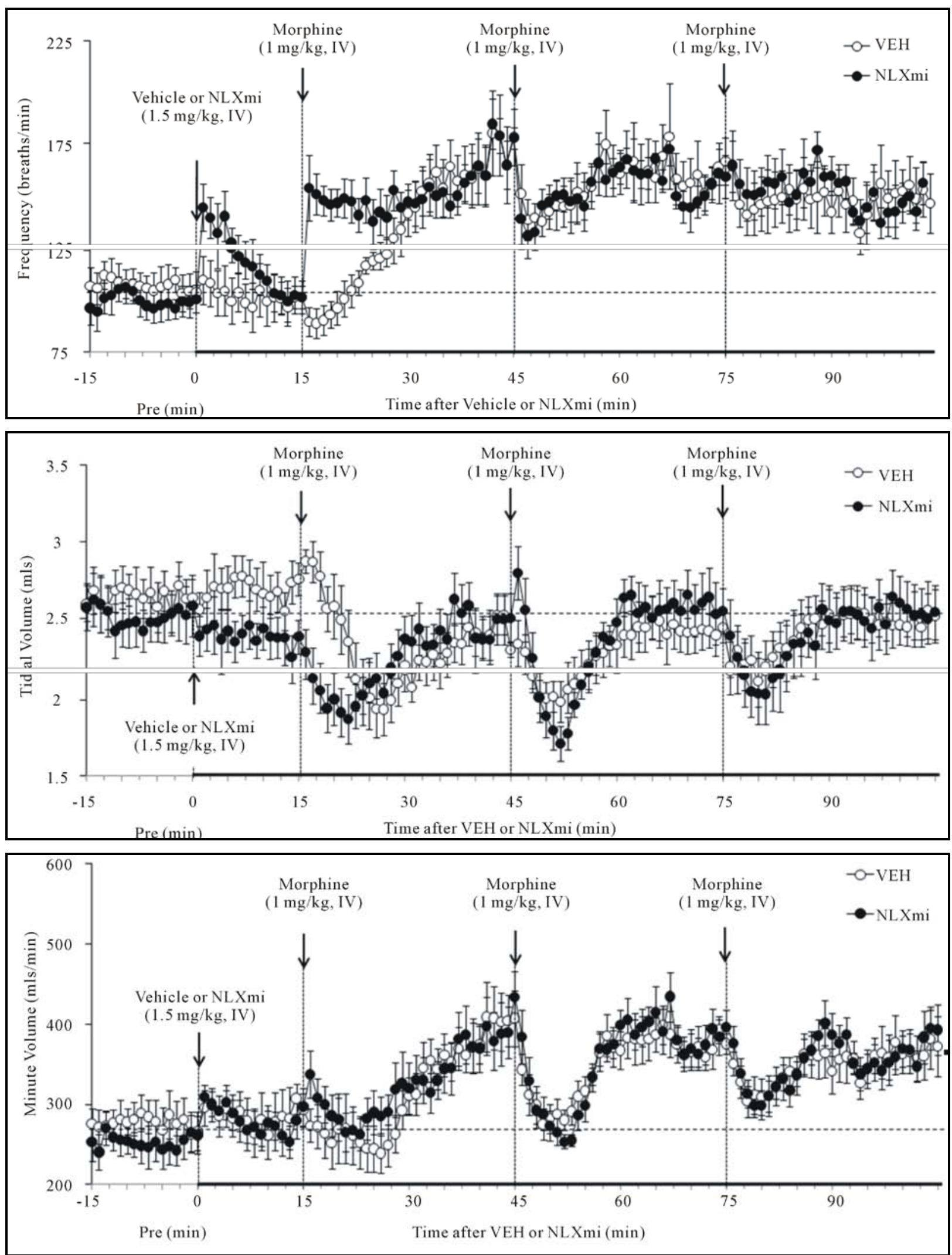

Figure 1. Frequency of breathing (top panel), tidal volume (middle panel) and minute volume (bottom panel)before (pre) and following bolus injections of vehicle or naloxone methiodide (NLXmi, $1.5 \mathrm{mg} / \mathrm{kg}, i . v$.) and subsequent injections of morphine $(1.0 \mathrm{mg} / \mathrm{kg}, i . v)$. The data are presented as mean \pm SEM. There were 9 rats in each group. 

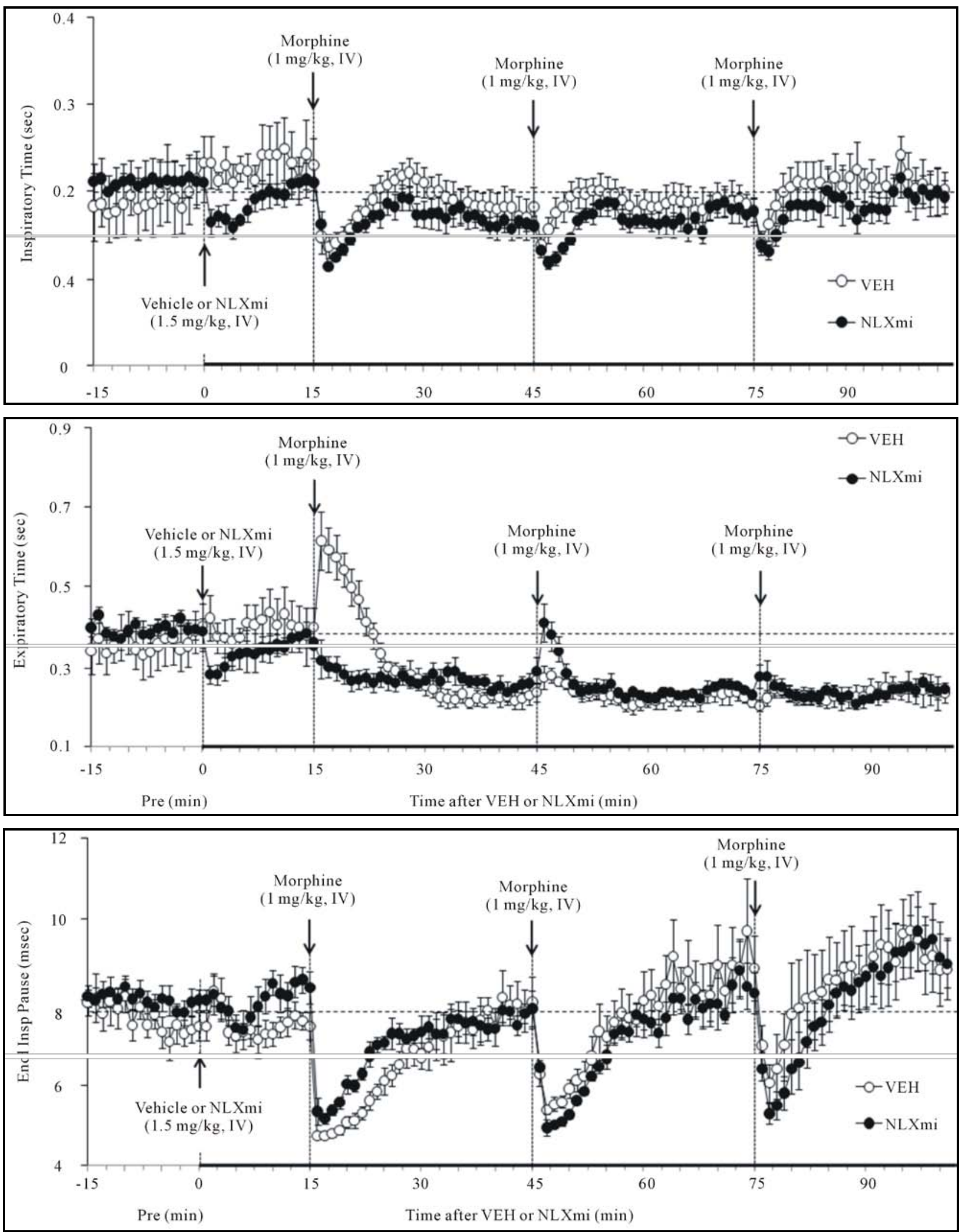

Figure 2. Inspiratory time (top panel), expiratory time (middle panel) and end inspiratory pause (bottom panel) before (pre) and following bolus injections of vehicle or naloxone methiodide (NLXmi, $1.5 \mathrm{mg} / \mathrm{kg}$, i.v.) and subsequent injections of morphine (1.0 $\mathrm{mg} / \mathrm{kg}, \mathrm{IV})$. The data are presented as mean \pm SEM. There were 9 rats in each group. 


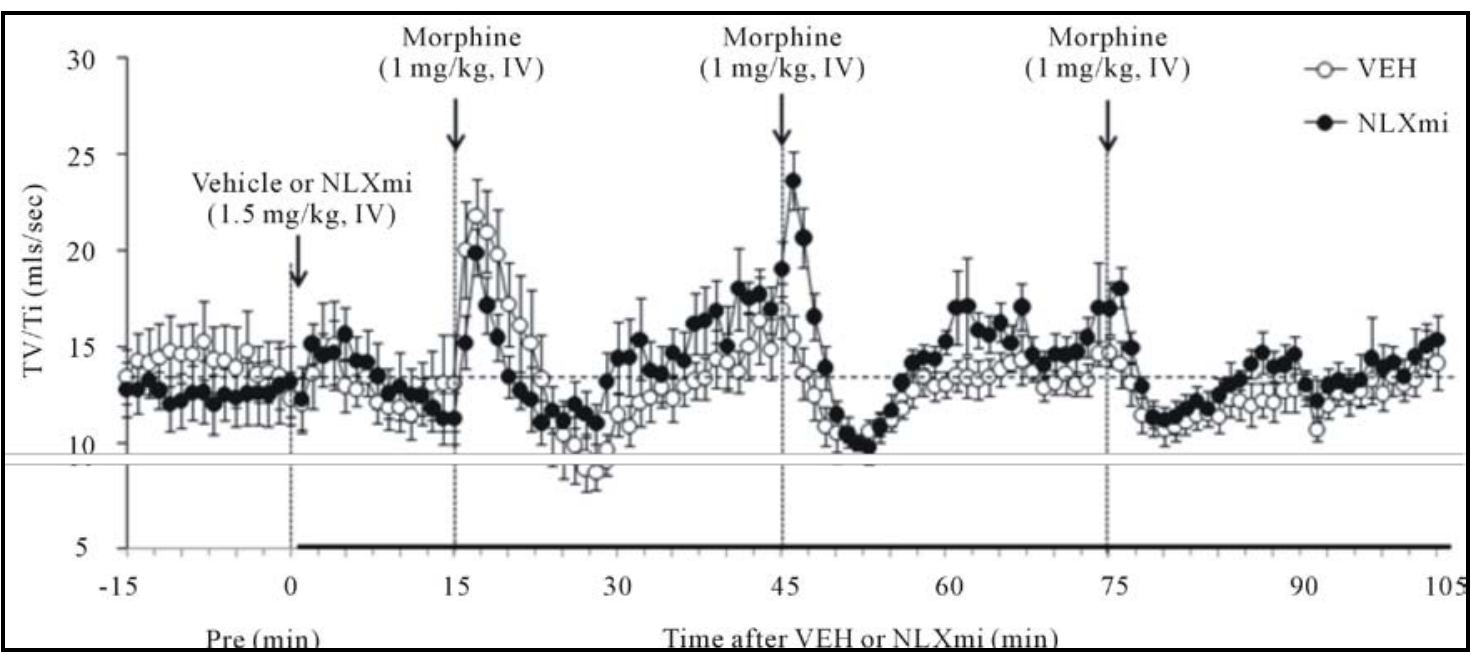

Figure 3. Respiratory drive (tidal volume/inspiratory time) before (pre) and following bolus injections of vehicle or naloxone methiodide (NLXmi, $1.5 \mathrm{mg} / \mathrm{kg}$, i.v.) and subsequent injections of morphine $(1.0 \mathrm{mg} / \mathrm{kg}, \mathrm{IV})$. The data are presented as mean \pm SEM. There were 9 rats in each group.
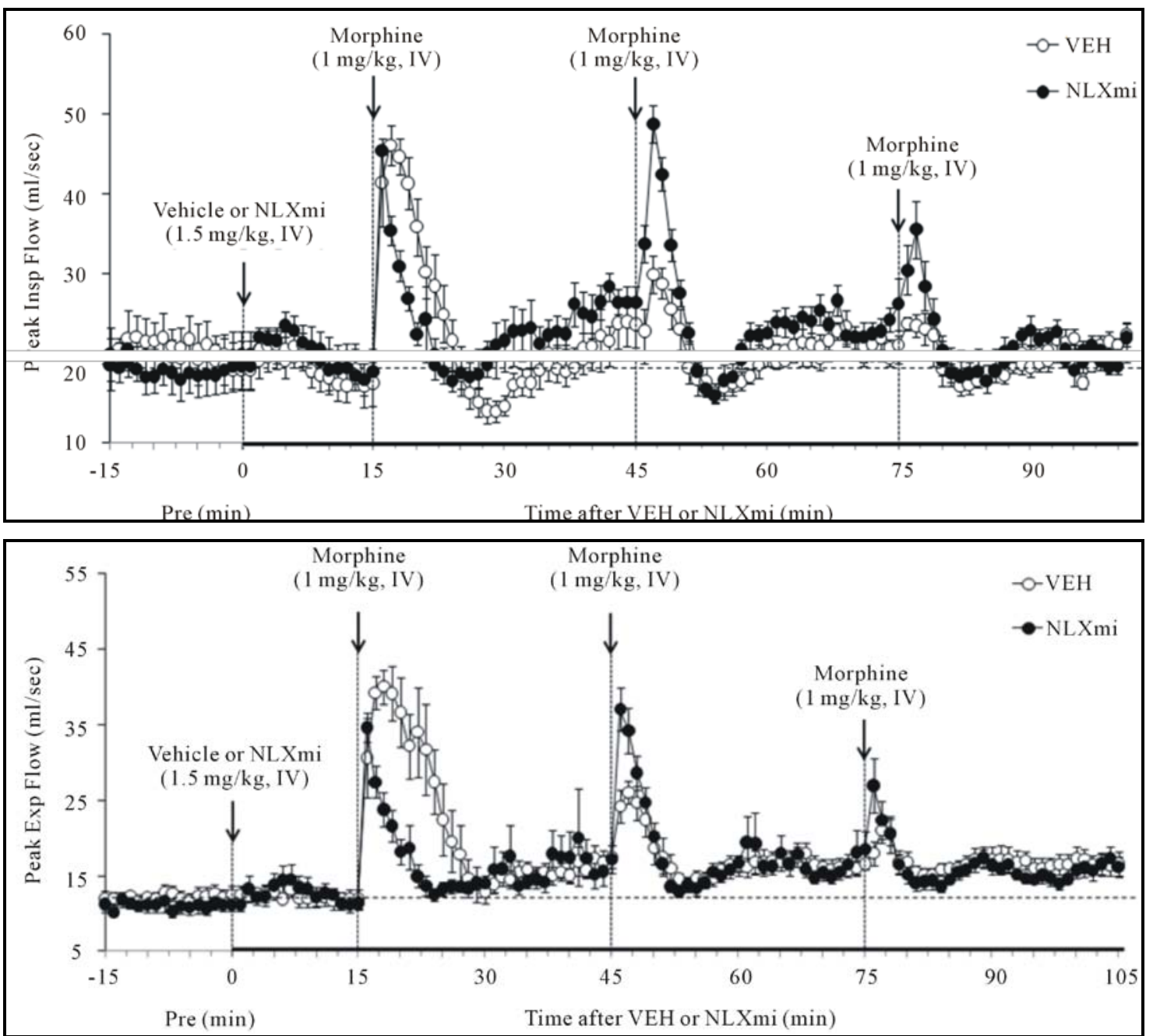

Figure 4. Peak inspiratory flow (top panel) and peak expiratory flow (bottom panel) before (pre) and following bolus injections of vehicle or naloxone methiodide (NLXmi, $1.5 \mathrm{mg} / \mathrm{kg}$, i.v.) and subsequent injections of morphine (1.0 $\mathrm{mg} / \mathrm{kg}, i . v$.). The data are presented as mean \pm SEM. There were 9 rats in each group. 
Table 2. Cumulative responses elicited by injections of vehicle or morphine (1 mg/kg, IV).

\begin{tabular}{|c|c|c|c|c|}
\hline \multirow[b]{2}{*}{ Parameter } & \multirow[b]{2}{*}{ Group } & \multicolumn{3}{|c|}{ Cumulative Responses } \\
\hline & & Injection 1 & Injection 2 & Injection 3 \\
\hline \multirow[t]{2}{*}{ Frequency, (breaths $/ \mathrm{min}) \times \min$} & Vehicle & $+1019 \pm 121^{*}$ & $-78 \pm 12^{* \ddagger}$ & $-9 \pm 6^{\ddagger}$ \\
\hline & NLXmi & $+1527 \pm 180^{* \dagger}$ & $-83 \pm 16^{* \ddagger}$ & $-10 \pm 6^{\ddagger}$ \\
\hline \multirow[t]{2}{*}{ Tidal volume $(\mathrm{mls}) \times \min$} & Vehicle & $-9.1 \pm 1.3^{*}$ & $-4.2 \pm 0.5^{* \ddagger}$ & $-2.7 \pm 0.4^{* \neq}$ \\
\hline & NLXmi & $-5.2 \pm 0.7^{* \dagger}$ & $-4.0 \pm 0.4^{*}$ & $-4.0 \pm 0.5^{*}$ \\
\hline \multirow[t]{2}{*}{ Minute volume $(\mathrm{mls} / \mathrm{min}) \times \min$} & Vehicle & $+1128 \pm 127^{*}$ & $-1687 \pm 159^{* \ddagger}$ & $-764 \pm 84^{* \neq}$ \\
\hline & NLXmi & $+1433 \pm 157^{*}$ & $-1599 \pm 185^{*}$ & $-867 \pm 92^{* \neq}$ \\
\hline \multirow[t]{2}{*}{ Inspiratory time $(\mathrm{sec}) \times \min$} & Vehicle & $-1.5 \pm 0.2^{*}$ & $+0.2 \pm 0.2^{\ddagger}$ & $+0.3 \pm 0.1^{\ddagger}$ \\
\hline & NLXmi & $-1.3 \pm 0.2^{*}$ & $+0.2 \pm 0.2^{\ddagger}$ & $+0.1 \pm 0.1^{\ddagger}$ \\
\hline \multirow[t]{2}{*}{ Expiratory time $(\mathrm{sec}) \times \min$} & Vehicle & $-2.2 \pm 0.3^{*}$ & $+0.1 \pm 0.4^{\ddagger}$ & $+0.5 \pm 0.3^{\ddagger}$ \\
\hline & NLXmi & $-3.4 \pm 0.3^{* \dagger}$ & $+0.1 \pm 0.3^{\ddagger}$ & $-0.4 \pm 0.2^{\ddagger}$ \\
\hline \multirow[t]{2}{*}{ End inspiratory pause $(\mathrm{msec}) \times \min$} & Vehicle & $-26 \pm 3^{*}$ & $-9 \pm 2^{* \ddagger}$ & $-12 \pm 3^{* \ddagger}$ \\
\hline & NLXmi & $-38 \pm 5^{*}$ & $-13 \pm 2^{* \ddagger}$ & $-11 \pm 2^{*, \neq}$ \\
\hline \multirow[t]{2}{*}{ Tidal volume/Inspiratory time $\times$ min } & Vehicle & $+27 \pm 6^{*}$ & $-96 \pm 5^{* \ddagger}$ & $-33 \pm 9^{* \ddagger}$ \\
\hline & NLXmi & $+80 \pm 16^{* \dagger}$ & $-85 \pm 17^{* \ddagger}$ & $-31 \pm 8^{* \ddagger}$ \\
\hline \multirow[t]{2}{*}{ Peak inspiratory flow $(\mathrm{mls} / \mathrm{sec}) \times \min$} & Vehicle & $+179 \pm 21^{*}$ & $-57 \pm 9^{*, \neq}$ & $-7 \pm 4^{\ddagger}$ \\
\hline & NLXmi & $+160 \pm 18^{*}$ & $-63 \pm 8^{* \ddagger}$ & $-6 \pm 3^{\ddagger}$ \\
\hline \multirow[t]{2}{*}{ Peak expiratory flow $(\mathrm{mls} / \mathrm{sec}) \times \min$} & Vehicle & $+290 \pm 33^{*}$ & $+14 \pm 2^{* \ddagger}$ & $+5 \pm 3^{\ddagger}$ \\
\hline & NLXmi & $+158 \pm 17^{* \dagger}$ & $+22 \pm 3^{* \ddagger}$ & $+7 \pm 3^{\ddagger}$ \\
\hline
\end{tabular}

Data are shown as mean \pm SEM. There were nine rats in each group. ${ }^{*} P<0.05$, significant response area. ${ }^{\dagger} P<0.05$, NLXmi versus vehicle. ${ }^{\ddagger} P<0.05$, injections 2 or 3 versus injection 1.

transient (i.e., 5 - 7 min) increase in TV/Ti (+8.1 \pm 1.2 $\mathrm{mls} / \mathrm{sec}$ at $+2 \mathrm{~min})$. This was due predominantly to the increase in TV/Ti was followed by a brief decrease $(-4.1$ $\pm 0.6 \mathrm{mls} / \mathrm{sec}$ at $+13 \mathrm{~min}$ ) due entirely to a decrease in TVsince Ti was minimally affected (see Figure 2). Inj$2 \mathrm{~m}$ did not elicit an initial increase $(+0.1 \pm 0.5 \mathrm{mls} / \mathrm{sec}$ at +2 min, $P>0.05)$ but did elicit a subsequent decrease $(-4.9 \pm 0.5 \mathrm{mls} / \mathrm{sec}$ at $+7 \mathrm{~min}, P<0.05)$. Inj-3m did not elicit an initial increase $(+0.3 \pm 0.3 \mathrm{mls} / \mathrm{sec}$ at $+2 \mathrm{~min}, P$ $>0.05)$ but did elicit a subsequent decrease $(-3.1 \pm 0.4$ mls/sec at +7 min, $P<0.05)$. Inj-1m elicited a similar increase in TV/Ti in NLXmi rats(+8.1 $\pm 1.2 \mathrm{mls} / \mathrm{sec})$ as in VEH rats $(P<0.05)$ although a secondary decrease was not observed $(-0.3 \pm 0.4 \mathrm{mls} / \mathrm{sec}$ at $+9 \mathrm{~min})$, perhaps because of the lower resting baseline prior to injection (Figure 3 and Table 1). Inj-2m elicited a greater increase in TV/Ti in NLXmi rats $(+4.8 \pm 0.4 \mathrm{mls} / \mathrm{sec}$ at $+1 \mathrm{~min})$ than in VEH rats $(P<0.05)$ whereas the secondary decrease $(-8.1 \pm 0.8 \mathrm{mls} / \mathrm{sec}$ at $+7 \mathrm{~min})$ was slightly greater than in VEH rats $(P<0.05)$. Inj-3m elicited a similar minimal increase in TV/Ti in NLXmi rats $(+1.3 \pm 0.6$ $\mathrm{mls} / \mathrm{sec}$ at $+1 \mathrm{~min})$ than in $\mathrm{VEH}$ rats $(P<0.05)$ whereas the secondary decrease $(-4.6 \pm 0.5 \mathrm{mls} / \mathrm{sec}$ at $+5 \mathrm{~min})$ was equal to than in VEH rats $(P>0.05)$. As seen in Table 2, inj-1m elicited a cumulative increase in TV/Ti in $\mathrm{VEH}$ rats whereas Injs-2m and $-3 \mathrm{~m}$ elicited substantial decreases (Inj-3 $<$ Inj-2, $P<0.05$ ). The cumulative response elicited by Inj-1m in NLXmi rats was greater than in VEH rats whereas the decreases elicited by Injs-2m and $-3 \mathrm{~m}$ were similar to those in $\mathrm{VEH}$ rats.

\subsubsection{Peak Inspiratory Flow}

Inj-1m in VEH rats (Figure 4 and Table 1) elicited a transient increase in PIF (+28 $\pm 4 \mathrm{mls} / \mathrm{sec})$. Inj-2m (+7 \pm $2 \mathrm{mls} / \mathrm{sec})$ and Inj-3m (+3 $\pm 2 \mathrm{mls} / \mathrm{sec})$ elicited substantially smaller responses. Inj-1m in NLXmi rats (Figure 4 and Table 1) elicited a similar increase in PIF (+26 \pm 5 $\mathrm{mls} / \mathrm{sec})$ to that in $\mathrm{VEH}$ rats $(P>0.05)$. Injs-2m and $-3 \mathrm{~m}$ elicited increases (+22 \pm 3 and $+11 \pm 3$ mls/sec, respectively) that were greater than in VEH rats $(P<0.05$, for both comparisons). As seen in Table 2, Inj-1m elicited a cumulative increase in PIF in VEH rats whereas Injs-2m and $-3 m$ elicited progressively smaller cumulative decreases. The cumulative responses elicited by injs-1m, $-2 m$ and $-3 m$ in NLXmi rats were similar to those in VEH rats.

\subsubsection{Peak Expiratory Flow}

Inj-1m in VEH rats (Figure 4 and Table 1) elicited a transient increase in PEF (+28 $\pm 4 \mathrm{mls} / \mathrm{sec})$. Inj-2m (+9 \pm $2 \mathrm{mls} / \mathrm{sec})$ and Inj-3m (+5 $\pm 2 \mathrm{mls} / \mathrm{sec})$ elicited substantially smaller responses. PEF remained at values slightly 
higher than pre-vehicle levels after each injection. Inj-1m in NLXmi rats (Figure 4 and Table 1) elicited a similar peak increase in PEF $(+22 \pm 3 \mathrm{mls} / \mathrm{sec})$ to that in $\mathrm{VEH}$ rats. However, Inj-2m elicited a somewhat greater increase $(+20 \pm 3 \mathrm{mls} / \mathrm{sec})$ than in $\mathrm{VEH}$ rats $(P<0.05)$ whereas Inj-3m elicited an increase $(+10 \pm 3 \mathrm{mls} / \mathrm{sec})$ that was similar to that in VEH rats $(P>0.05)$. Inj-1m elicited a cumulative increase in PEF in VEH rats whereas Injs-2m and -3m elicited progressively smaller cumulative responses (Table 2). The cumulative response elicited by Inj-1m in NLXmi rats was smaller than in VEH rats whereas those elicited by Inj-2m and -3m were similar to VEH rats.

\section{DISCUSSION}

\subsection{Ventilatory Responses Elicited by NLXmi}

NLXmi elicited a transient increase in frequency of breathing that was associated with minor decreases in TV. These changes resulted in a relatively minor increase in MV. Although it is possible that NLXmi indirectly affected ventilation by altering the state of arousal, no differences in behavior between VEH and NLXmi rats were observed. This is consistent with evidence that NLXmi does not enter the central nervous system [40-43]. Based on the known receptor pharmacology of NLXmi, that is preference for $\mu$-ORs but with some activity at $\delta$-Ors. see $[38,39]$, the ventilatory responses elicited by NLXmi are consistent with the possibility that endogenous morphine [47] and opioid peptides (e.g., endomorphins, enkaphalins) with activity at $\mu$ - and/or $\delta$-ORs $[9,48,49]$ play a tonic role in the peripheral (e.g., carotid body) control of breathing $[7,9]$.

\subsection{Morphineresponses-Tolerance and Role of Central and Peripheral Opioid Receptors}

Lower doses of opioids such as morphine, [D-Pen ${ }^{2}$, D$\mathrm{Pen}^{5}$ ] enkephalin, dermorphin and fentanyl stimulate ventilation via effects blocked by systemic injection of the centrally-penetrant $\mu$-OR preferring antagonist, naloxone $[32,33,35]$. In our study, Inj-1m elicited a gradual and sustained increase in Frequency in VEH rats whereas it elicited an immediate increase and sustained increase in NLXmi rats. Taken together, our results suggest that the ability of morphine to increase Frequency is due to activation of central $\mu$-and/or $\delta$-ORs and that activation of peripheral $\mu$-and/or $\delta$-ORs masks these central actions. Inj-2m elicited a substantial but relatively transient decrease in Frequency in VEH rats whereas Inj-3m elicited a minor decrease. Since these responses were virtually identical in NLXmi rats, it appears that the ability of Inj-2m to decrease Frequency was due to activation of central $\mu$-and/or $\delta$-ORs, which would be different in terms of cell location from those that increase Frequency.
Specifically, the predominant pre-synaptic localization of $\mu$-ORs [50] raises the possibility that the Inj-1m increases Frequency by inhibiting the activity of central pathways that suppress the tonic firing of neurons driving ventilation. In contrast, Inj-2mmay transiently inhibit the activity of central pathways that excite these neurons or those mediating the tonic increase in activity. Since baseline Frequency remained elevated throughout the study, it is evident that the mechanisms driving Frequency are not readily subject to the development of tolerance. Although the mechanisms which allow morphine to elicit transient decrease in ventilation in the face of elevated respiratory frequency are not known, it is evident that they are subject to tolerance. These findings suggest that ORs mediating the excitatory and inhibitory effects of morphine on Frequency are differentially susceptible to desensitization.

The above changes in Frequency were associated with equally complex changes in $\mathrm{Ti}$ and Te. The first injection of morphine elicited a prompt decrease in Ti (inspiration was more rapid) of about $10 \mathrm{~min}$ in duration. The initial decrease in $\mathrm{Ti}$ is consistent with the increased frequency of breathing and suggests that morphine did not initially inhibit the mechanisms responsible for accelerating active inspiration. However, whereas the increase in Frequency was sustained, the decrease in Ti was not. As such, it is possible that morphine gradually impairs the systems accelerating active inspiratory timing. Since the sustained increase in Frequency was associated with a sustained decrease in Te, it appears that the predominant effect on respiratory timing during the sustained phase of increased frequency was to elicit more rapid expiration. It should be noted that the initial increases in Frequency were accompanied by an equally prompt increase rather than a decrease in Te of $6-7 \mathrm{~min}$ in duration. The increase in Te may involve the propensity of morphine to increase airways resistance that manifests particularly during passive exhalation $[14,15]$. The findings that the ability of morphine to transiently decrease Ti was subject to tolerance and that the pattern of responses elicited by Injs1-3m was similar in the NLX mi rats suggests that morphine-induced acceleration of inspiration was due to activation of central $\mu$-and/or $\delta$-ORs that were subject to rapid desensitization. The initial increase in Te elicited by the Inj-1m in VEH rats was not elicited by subsequent injections. The finding that this initial increase was absent in NLXmi rats suggests that the loss of the ability of morphine to lengthen Te was due to desensitization of peripheral $\mu$-and/or $\delta$-ORs. In contrast, the sustained ability of morphine to decrease Te in VEH and NLX mi rats suggests that the central $\mu$-and/or $\delta$-ORs driving active expiration are not readily subject to desensitization. Moreover, that Inj-2m elicited a transient increase in Te in NLX mi rats argues that blockade of peripheral $\mu$ - and/or 
$\delta$-ORs allows morphine to lengthen respiratory duration by actions on $\mu$ - and/or $\delta$-ORs in the brain. The observation that Inj-3m did not elicit this response in NLXmi rats is evidence that $\mu$ - and/or $\delta$-ORs mediating this effect of expiratory timing are also subject to down-regulation. The findings that Inj-1m in VEH rats increased EIP (delay between the end of inspiration and the start of expiration) and that this increase was not affected by NLXmi, is consistent with morphine inhibiting the central timing of breathing. Moreover, the finding that the ability of subsequent injections to diminish EIP was markedly and equally diminished in the VEH or NLXmi rats again suggest that that tolerance to this effect of morphine is due to the desensitization/down- regulation of central $\mu$ and/or $\delta$-ORs.

In contrast to the complex changes in Frequency, morphine consistently decreased TV in VEH and NLXmi rats. Although the ability of morphine to maximally decrease TV was not subject to tolerance in VEH rats (i.e., the peak responses elicited by Injs1-3m were similar to one another), the overall (cumulative) decreases in TV elicited by Injs-2m and -3m were progressively and substantially smaller than that of Inj-1m. The ability of NLX mi to attenuate the cumulative (but not the initial maximal) decrease in TV elicited by Inj-1m implicates peripheral ORs and perhaps those within the neuromuscular system controlling TV. However, Injs-2m and $-3 m$ in NLX mi rats elicited similarly diminished responses to those in VEH rats. Since NLX mi minimally affected the responses elicited by $\mathrm{Inj}-1 \mathrm{~m}$ and did not affect the development of tolerance to these responses, it is evident that blockade of peripheral $\mu$ - and/or $\delta$-ORs is not sufficient to block the initial decreases in TV or the desensitization/down-regulation of ORs that mediate these responses. Taken together, it is likely the ability of morphine to decrease TV is due to activation of central $\mu$ and/or $\delta$-ORs and that development of tolerance is due desensitization/down-regulation of these receptors.

The changes in MV elicited by the injections of morphine highlight the complex nature of the ventilatory pattern elicited by the opioid agonist, and if looked at in isolation, would not ascribe a role of peripheral ORs in these responses. Specifically, Inj-1m elicited a gradual and sustained increase in MV that was qualitatively and quantitatively similar in VEH and NLX mi rats whereas subsequent injections elicited transient decreases in MV that were also very similar in both groups. The lack of change in MV over the first 5 min in VEH rats following Inj-1m was due to lack of changes in Frequency and TV whereas the lack of change in MV at 10 - 15 min was due to relatively equivalent increases in Frequency and decreases in TV. The increases in MV between 15 - 30 min were due solely to the increase in Frequency since TV recovered to pre-injection levels. In contrast, the lack of change in MV over the first 15 min in NLXmi rats was due to robust increases in Frequency being counter balanced by equally robust decreases in TV. As in the $\mathrm{VEH}$ rats, the increase in MV was due entirely to the increase in Frequency. The ability of subsequent injections of morphine to depress ventilatory function are clearly supported by the findings that Inj-2m, and to a much lesser degree Inj-3m, elicited decreases in MV. The findings that the responses elicited by Injs2-3m were virtually identical in $\mathrm{VEH}$ and NLXmi rats supports the above contention that the decreases in MV (via decreases in Frequency and TV) involves central $\mu$ - and/or $\delta$-ORs and that development of tolerance is due the desensitization/down-regulation of these receptors.

The finding that Inj-1m in VEH rats elicited a relatively transient but nevertheless robust increase in TV/Ti, an index of Respiratory Drive [45], clearly supports the concept that a low dose of morphine can increase ventilatory drive. However, the change in this ratio may be somewhat misleading since both TV and Ti decreased. However, since the decrease in TV was relatively less than the decrease in $\mathrm{Ti}$, it at appears that morphine recruited mechanisms designed to limit the ventilatory depressant effects of the opioid. Since the initial increase in Respiratory Drive was similar in VEH and NLXmi rats, it is apparent that this phenomenon is due to activation of central $\mu$ - and/or $\delta$-ORs. One interesting finding was that whereas Inj-2m did not elicit an initial increase in Respiratory Drive in VEH rats, a relatively robust increase (due to maintenance of TV coupled to a decrease in Ti) was observed in NLX mi rats. This finding suggests that blockade of peripheral $\mu$ - and/or $\delta$-OR sallows for the robust increase in Respiratory Drive. The initial morphine-induced increases in Respiratory Drive in VEH rats were followed by brief decreases (due principally to the decrease in TV). As expected from the changes in TV and $\mathrm{Ti}$ in the $\mathrm{VEH}$ or NLXmi rats, it was evident that these cumulative decreases diminished with each injection of morphine and that the response patterns were not affected by NLXmi. This supports the contention that central $\mu$ - and/or $\delta$-Ors are critically involved in mediating the depressant effects of morphine on Respiratory Drive and that these receptors are subject to desensitization. Finally, whereas Inj-1m substantially increased PIF and PEF in VEH rats, subsequent injections elicited substantially and progressively smaller responses. Again, this is a clear demonstration that tolerance can develop rapidly to the ventilatory excitatory actions of a low dose of morphine. Since NLXmi did not affect the responses elicited by Inj-1m or development of tolerance to these responses it is evident that blockade of peripheral $\mu$ and/or $\delta$-Ors (including those within the neuromusculature of the chest and wall and diaphragm) is not sufficient to block the initial actions of morphine, or the de- 
sensitization and/or down-regulation of the presumably central ORs that mediate the increases PIF and PEF.

\subsection{Potential Mechanisms Responsible for the Development of Tolerance}

Although there is a direct relationship between the efficacy of $\mu$-OR agonists and development of tolerance, morphine produces greater tolerance than other opioids of similar efficacy [50]. Since this enhanced tolerance occurs despite morphine not efficiently promoting the removal of $\mu$-ORs from the plasma membranes of cells, (i.e., down-regulation) [51,52], it would appear that intracellular cascades promoting the loss of efficacy of $\mu$-ORs (i.e., desensitization) are involved [50]. Although the mechanisms responsible for the (putative) desensitization of $\mu$-ORs responsible for the ventilatory and excitatory effects of morphine have not been established, numerous molecular mechanisms are known to contribute to the desensitization of these receptors [50,53-55]. We recently provided evidence that co-activation of $\mu$ and $\delta$-ORs elicits tolerance to morphine-induced ventilatory depression via generation of peroxynitrite [10]. It should be noted that mechanisms that down-regulate the effects of morphine may be unique and not pertain to those down-regulating the efficacy of more selective/ potent $\mu$-OR agonists such as fentanyl [50].

\subsection{Are the Effects of NLXmi on Morphine-Induced Ventilatory Responses Necessarily Peripheral?}

Compelling evidence exists that NLXmi does not cross the blood-brain barrier in rodents after peripheral administration [40-43]. This evidence includes that 1) subcutaneous injection of NLXmi $(10 \mathrm{mg} / \mathrm{kg})$ did not affect the antinociceptive effects of morphine given centrally in rats whereas a lesser dose of NLX $(1 \mathrm{mg} / \mathrm{kg})$ had substantial effects [42], and 2) a large subcutaneous dose of NLXmi $(100 \mathrm{mg} / \mathrm{kg})$ did not precipitate withdrawal symptoms in morphine-tolerant mice whereas a lower dose of NLX (3 mg/kg) elicited pronounced withdrawal behaviors [40]. Accordingly, it is tempting to assume that NLXmi modify the ventilatory effects of morphinevia blockade of $\mu_{1,2}$-ORs in peripheral structures such as the carotid bodies. The present findings certainly support evidence that the ventilatory depressant effects of opioids involve activation of peripheral ORs [see 40,41]. However, it should be recognized that the ventilatory effects of systemically-injected OR agonists and antagonists may involve actions on ORs in brain structures devoid of a blood-brain barrier such as the area postrema. see [56,57], sites that would be readily accessible to NLXmi. These structures express neuronal $\mu$-, $\delta$-and $\kappa$-ORs [58-61], and direct injections of opioid receptor agonists into these structures elicit physiological responses [6264]. A clear example of a role of circumventricular organs in the actions of opioids and NLXmi arises from findings that emesis in ferrets elicited by subcutaneous injection of the $\mu$-OR agonist, loperamide $(0.5 \mathrm{mg} / \mathrm{kg})$, was equally abolished by prior subcutaneous injections of a $1 \mathrm{mg} / \mathrm{kg}$ dose of or NLXmi (or the centrally penetrant opioid receptor antagonist, naloxone), or by prior ablation of the area postrema [62]. The effects of direct injections of opioids into circum ventricular organs on ventilatory parameters have not been reported. Nonetheless, these structures are involved in ventilatory control [65-67]. As such, the ventilatory actions of morphine (both excitatory and inhibitory) may involve direct effects on ORs in the circum ventricular organs that would also be accessible to NLXmi.

\section{CONCLUSION}

Inj-1 of low-dose morphine $(1 \mathrm{mg} / \mathrm{kg}$, i.v.) in VEH rats elicited ventilatory excitant responses such as increases in Frequency (accompanied by decreases in Ti and EIP), MV, Respiratory Drive, PIF and PEF. This injection also elicited ventilatory inhibitory responses such as a decrease in TV and an increase in Te. The observation that subsequent injections of morphine elicited progressively smaller responses suggests that tolerance occurred and that this phenomenon elicited by low doses of morphine occurred in a relatively rapid manner. Since the pattern of responses elicited by Inj-1m was substantially affected by pretreatment with NLX mi, it appears that peripheral $\mu$-ORs are involved in these responses. However, since NLX mi minimally affected the development of tolerance to these responses, it appears that tolerance involves the loss of function of central $\mu$-ORs. The molecular mechanisms underlying the development of tolerance to the ventilatory actions of low doses of morphine remain to be established see [50]. Moreover, since morphine depresses the ventilatory responses to hypoxia and/hypercapnia in man and animals via actions in the brain and carotid bodies $[7,68]$, the possibility that the effects of low doses of morphine affect ventilatory parameters "indirectly" via actions on cell systems designed to respond to changes in arterial blood gas status cannot be discounted.

\section{REFERENCES}

[1] Oguri, K., Yamada-Mori, I., Shigezane, J., Hirano, T. and Yoshimura, H. (1987) Enhanced binding of morphine and nalorphine to opioid delta receptor by glucuronate and sulfate conjugations at the 6-position. Life Sciences, 41, 1457-1464. doi:10.1016/0024-3205(87)90710-7

[2] Frances, B., Gout, R., Campistron, G., Panconi, E. and Cros, J. (1990) Morphine-6-glucuronide is more $\mu$-selec- 
tive and potent in analgesic tests than morphine. Progress in Clinical Biological Research, 328, 477-480.

[3] Frances, B., Gout, R., Monsarrat, B., Cros, J. and Zajac, J.M. (1992) Further evidence that morphine-6 beta-glucuronide is a more potent opioid agonist than morphine. Journal of Phrmacology and Experimental Therapeutics, 262, 25-31.

[4] Chen, Z.R., Irvine, R.J., Somogyi, A.A. and Bochner, F. (1991) Mu receptor binding of some commonly used opioids and their metabolites. Life Sciences, 48, 2165-2171. doi:10.1016/0024-3205(91)90150-A

[5] Christensen, C.B. and Reiff, L. (1991) Morphine-6-glucuronide: Receptor binding profile in bovine caudate nucleus. Pharmacology and Toxicology, 68, 151-153. doi:10.1111/j.1600-0773.1991.tb02056.x

[6] Trescot, A.M., Datta, S., Lee, M. and Hansen, H. (2008) Opioid pharmacology. Pain Physician, 11, S133-S153.

[7] Dahan, A., Aarts, L. and Smith, T.W. (2010) Incidence, reversal, and prevention of opioid-induced respiratory depression. Anesthesiology, 112, 226-238. doi:10.1097/ALN.0b013e3181c38c25

[8] Yeadon, M. and Kitchen, I. (1989) Opioids and respiration. Progress in Neurobiology, 33, 1-16. doi:10.1016/0301-0082(89)90033-6

[9] Shook, J.E., Watkins, W.D. and Camporesi, E.M. (1990) Differential roles of opioid receptors in respiration, respiratory disease, and opiate-induced respiratory depresssion. American Review of Respiratory Disease, 142, 895909. doi:10.1164/ajrccm/142.4.895

[10] Young, A.P., Gruber, R.B., Discala, J.F., May, W.J., Palmer, L.A. and Lewis, S.J. (2013) Co-activation of $\mu$ - and $\delta$-opioid receptors elicits tolerance to morphine-induced ventilatory depression via generation of peroxynitrite. Respiratory Physiology and Neurobiology, 186, 255-264. doi:10.1016/j.resp.2013.02.028

[11] Campbell, C., Weinger, M.B. and Quinn, M. (1995) Alterations in diaphragm EMG activity during opiate-induced respiratory depression. Respiratory Physiology, 100, 107-117. doi:10.1016/0034-5687(94)00119-K

[12] Kaczyńska, K. and Szereda-Przestaszewska, M. (2005) Involvement of vagal opioid receptors in respiratory effects of morphine in anaesthetized rats. Journal of Physiology and Pharmacology, 56, 195-203.

[13] Niedhart, P., Burgener, M.C., Schweiger, J. and Suter, P.M. (1989) Chest wall rigidity during fentanyl and midazolam-fentanyl induction: Ventilatory and hemodynamic effects. Acta Anaesthesiologica Scandinavia, 33, 1-5. doi:10.1111/j.1399-6576.1989.tb02849.x

[14] Willette, R.N., Barcas, P.P., Krieger, A.J. and Sapru, H.N. (1983) Pulmonary resistance and compliance changes evoked by pulmonary opiate receptor stimulation. European Journal of Pharmacology, 91, 181-188. doi:10.1016/0014-2999(83)90463-6

[15] Willette, R.N., Krieger, A.J. and Sapru, H.N. (1982) Opioids increase laryngeal resistance and motoneuron activeity in the recurrent laryngeal nerve. European Journal of Pharmacology, 80, 57-63. doi:10.1016/0014-2999(82)90177-7
[16] Zhang, Z., Xu, F., Zhang, C. and Liang, X. (2009) Opioid $\mu$-receptors in medullary raphe region affect the hypoxic ventilation in anesthetized rats. Respiratory Physiology and Neurobiology, 168, 281-288. doi:10.1016/j.resp.2009.07.015

[17] McQueen, D.S. and Ribeiro, J.A. (1980) Inhibitory actions of methionine-enkephalin and morphine on the cat carotid chemoreceptors. British Journal of Pharmacology, 71, 297-305.

[18] Zimpfer, M., Beck, A., Mayer, N., Raberger, G. and Steinbereithner, K. (1983) Effects of morphine on the control of the cardiovascular system by the carotid-sinus-reflex and by the carotid chemoreflex. Anaesthesist, 32, 60-66.

[19] Kirby, G.C. and McQueen, D.S. (1986) Characterization of opioid receptors in the cat carotid body involved in chemosensory depression in vivo. British Journal of Pharmacology, 88, 889-898. doi:10.1111/j.1476-5381.1986.tb16263.x

[20] Verborgh, C. and Camu, F. (1990) Post-surgical pain relief with zero-order intravenous infusions of meptazinol and morphine: A double-blind placebo-controlled evaluation of their effects on ventilation. European Journal of Clinical Pharmacology, 38, 437-442. doi:10.1007/BF02336680

[21] Reisine, T. and Pasternak, G. (1995) Opioid analgesics and antagonists. In: Hardman, J.G., Limbird, L.E., Molinoff, P.B., Ruddon, R.W. and Gilman, A.G., Eds., 9th Edition, Goodman and Gilman's the Pharmacological Basis of Therapeutics, McGraw-Hill, New York, pp. 521-556.

[22] Freye, E. and Latasch, L. (2003) Development of opioid tolerance-Molecular mechanisms and clinical conesquences. Anasthesiol Intensivmed Notfallmed Schmerzther, 38, 14-26. doi:10.1055/s-2003-36558

[23] Risdahl, J.M., Chao, C., Murtaugh, M.P., Peterson, P.K. and Molitor, T.W. (1992) Acute and chronic morphine administration in swine. Pharmacology Biochemistry and Behavior, 43, 799-806. doi:10.1016/0091-3057(92)90411-8

[24] Hovav, E. and Weinstock, M. (1987) Temporal factors influencing the development of acute tolerance to opiates. Journal of Pharmacology and Experimental Therapeutics, 242, 251-256.

[25] Bowen, S.R., Carpenter, F.G. and Sowell, J.G. (1979) Ventilatory depression in naive and tolerant rats in re- lation to plasma morphine concentration. British Journal of Pharmacology, 65, 457-463. doi:10.1111/j.1476-5381.1979.tb07851.x

[26] McGilliard, K.L. and Takemori, A.E. (1978) Alterations in the antagonism by naloxone of morphine-induced respiratory depression and analgesia after morphine pretreatment. Journal of Pharmacology and Experimental Therapeutics, 207, 884-891.

[27] Roerig, S.C., Fujimoto, J.M. and Lange D.G. (1987) Development of tolerance to respiratory depression in morphine- and etorphine-pellet-implanted mice. Brain Research, 400, 278-284. doi:10.1016/0006-8993(87)90627-5

[28] Martin, W.R. and Jasinski, D.R. (1969) Physiological 
parameters of morphine dependence in man-tolerance, early abstinence, protracted abstinence. Journal of Psychiatric Research, 7, 9-17. doi:10.1016/0022-3956(69)90007-7

[29] Paronis, C.A. and Woods, J.H., (1997) Ventilation in morphine-maintained rhesus monkeys. II: Tolerance to the antinociceptive but not the ventilatory effects of morphine. Pharmacology and Experimental Therapeutics, 282, 355-362.

[30] Kishioka, S., Paronis, C.A. and Woods, J.H. (2000) Acute dependence on, but not tolerance to, heroin and morphine as measured by respiratory effects in rhesus monkeys. European Journal of Pharmacology, 398, 121-130. doi:10.1016/S0014-2999(00)00279-X

[31] Ling, G.S., Paul, D., Simantov, R. and Pasternak, G.W. (1989) Differential development of acute tolerance to analgesia, respiratory depression, gastrointestinal transit and hormone release in a morphine infusion model. Life Sciences, 45, 1627-1636. doi:10.1016/0024-3205(89)90272-5

[32] Szeto, H.H., Cheng, P.Y., Dwyer, G., Decena, J.A., Wu, D.L. and Cheng, Y. (1991) Morphine-induced stimulation of fetal breathing: Role of mu 1-receptors and central muscarinic pathways. American Journal of PhysiologyRegulatory, Integrative and Comparative Physiology, 261, R344-R350.

[33] Cheng, P.Y., Wu, D., Soong, Y., McCabe, S., Decena, J.A. and Szeto, H.H. (1993) Role of $\mu_{1}$ - and $\delta$-opioid receptors in modulation of fetal EEG and respiratory activity. American Journal of Physiology-Regulatory, Integrative and Comparative Physiology, 265, R433-R438.

[34] Paakkari, P., Paakkari, I., Sirén, A.L. and Feuerstein, G. (1990) Respiratory and locomotor stimulation by low doses of dermorphin, a $\mathrm{Mu}_{1}$ receptor-mediated effect. Journal of Pharmacology and Experimental Therapeutics, 252, 235-240.

[35] Horita, A., Carino, M.A. and Chinn, C. (1989) Fentanyl produces cholinergically-mediated analeptic and EEG arousal effects in rats. Neuropharmacology, 28, 481-486. doi:10.1016/0028-3908(89)90083-X

[36] Kayser, V., Chen, Y.L. and Guilbaud, G. (1991) Behavioural evidence for a peripheral component in the enhanced antinociceptive effect of a low dose of systemic morphine in carrageenin-induced hyperalgesic rats. Brain Research, 560, 237-244. doi:10.1016/0006-8993(91)91238-V

[37] Tamaddonfard, E. and Hamzeh-Gooshchi, N. (2010) Effect of crocin on the morphine-induced antinociception in the formalin test in rats. Phytotherapy Research, 24, 410413. doi:10.1002/ptr.2965

[38] Deviche, P. (1997) Affinity of naloxone and its quarternary analogue for avian central delta and mu opioid receptors. Brain Research, 757, 276-279. doi:10.1016/S0006-8993(97)00298-9

[39] Lewanowitsch, T. and Irvine, R.J. (2003) Naloxone and its quaternary derivative, naloxone methiodide, have differing affinities for mu, delta, and kappa opioid receptors in mouse brain homogenates. Brain Research, 964, 302305. doi:10.1016/S0006-8993(02)04117-3

[40] Lewanowitsch, T. and Irvine, R.J. (2002) Naloxone me- thiodide reverses opioid-induced respiratory depression and analgesia without withdrawal. European Journal of Pharmacology, 445, 61-67. doi:10.1016/S0014-2999(02)01715-6

[41] Lewanowitsch, T., Miller, J.H. and Irvine, R.J. (2006) Reversal of morphine, methadone and heroin induced effects in mice by naloxone methiodide. Life Sciences, 78, 682-688. doi:10.1016/j.lfs.2005.05.062

[42] He, L., Kim, J., Ou, C., McFadden, W., van Rijn, R.M. and Whistler, J.L. (2009) Methadone antinociception is dependent on peripheral opioid receptors. Journal of Pain, 10, 369-379. doi:10.1016/j.jpain.2008.09.011

[43] Yamamoto, A., Kuyama, S., Kamei, C. and Sugimoto, Y. (2010) Characterization of scratching behavior induced by intradermal administration of morphine and fentanyl in mice. European Journal of Pharmacology, 627, 162166. doi:10.1016/j.ejphar.2009.10.066

[44] Kanbar, R., Stornetta, R.L., Cash, D.R., Lewis, S.J. and Guyenet, P.G. (2010) Photostimulation of Phox2b medullary neurons activates cardiorespiratory function in conscious rats. American Journal of Respiratory Critical Care Medicine, 182, 1184-1194. doi:10.1164/rccm.201001-0047OC

[45] Laferriere, A., Colin-Durand, J. and Moss, I.R. (2005) Ontogeny of respiratory sensitivity and tolerance to the mu-opioid agonist fentanyl in rat. Develop. Brain Research, 156, 210-217. doi:10.1016/j.devbrainres.2005.03.002

[46] Wallenstein, S., Zucker, C.L. and Fleiss, J.L. (1980) Some statistical methods useful in circulation research. Circulation Research, 47, 1-9. doi:10.1161/01.RES.47.1.1

[47] Stefano, G.B., Kream, R.M. and Esch, T. (2009) Revisiting tolerance from the endogenous morphine perspective. Medical Science Monitor, 15, RA189-RA198.

[48] Drake, C.T., Chavkin, C. and Milner, T.A. (2007) Opioid systems in the dentate gyrus. Progress in Brain Research, 163, 245-263. doi:10.1016/S0079-6123(07)63015-5

[49] Keresztes, A., Borics, A. and Tóth G. (2010) Recent advances in endomorphin engineering. ChemMedChem, 5, 1176-1196. doi:10.1002/cmdc.201000077

[50] Connor, M., Osborne, P.B. and Christie, M.J. (2004) $\mu$ opioid receptor desensitization: Is morphine different? British Journal of Pharmacology, 143, 685-696. doi:10.1038/sj.bjp.0705938

[51] Von Zastrow, M., Svingos, A., Haberstock-Debic, H. and Evans, C. (2003) Regulated endocytosis of opioid receptors: Cellular mechanisms and proposed roles in physiological adaptation to opiate drugs. Current Opinions in Neurobiology, 13, 348-353. doi:10.1016/S0959-4388(03)00069-2

[52] Waldhoer, M., Bartlett, S.E. and Whistler, J.L. (2004) Opioid receptors. Annual Reviews of Biochemistry, 73, 953-990. doi:10.1146/annurev.biochem.73.011303.073940

[53] Bailey, C.P. and Connor, M. (2005) Opioids: Cellular mechanisms of tolerance and physical dependence. Current Opinions in Pharmacology, 5, 60-68. doi:10.1016/j.coph.2004.08.012 
[54] Bailey, C.P., Oldfield, S., Llorente, J., Caunt, C.J., Teschemacher, A.G., Roberts, L., McArdle, C.A., Smith, F.L., Dewey, W.L., Kelly, E. and Henderson, G. (2009) Involvement of PKC $\alpha$ and G-protein-coupled receptor kinase 2 in agonist-selective desensitization of $\mu$-opioid receptors in mature brain neurons. British Journal of Pharmacology, 158, 157-164.

doi:10.1111/j.1476-5381.2009.00140.x

[55] Salvemini, D. and Neumann, W.L. (2009) Peroxynitrite: A strategic linchpin of opioid analgesic tolerance. Trends in Pharmacological Sciences, 30, 194-202. doi:10.1016/j.tips.2008.12.005

[56] Borison, H.L. (1989) Area postrema: Chemoreceptor circumventricular organ of the medulla oblongata. Progress in Neurobiology, 32, 351-390. doi:10.1016/0301-0082(89)90028-2

[57] Duvernoy, H.M. and Risold, P.Y. (2007) The circumventricular organs: An atlas of comparative anatomy and vascularization. Brain Research Reviews, 56, 119-147. doi:10.1016/j.brainresrev.2007.06.002

[58] Atweh, S.F. and Kuhar, M.J. (1977) Autoradiographic localization of opiate receptors in rat brain. III. The telencephalon. Brain Research, 134, 393-405. doi:10.1016/0006-8993(77)90817-4

[59] Moskowitz, A.S. and Goodman, R.R. (1984) Light microscopic autoradiographic localization of mu and delta opioid binding sites in the mouse central nervous system. Journal of Neuroscience, 4, 1331-1342.

[60] Guan, J.L., Wang, Q.P. and Nakai, Y. (1999) Electron microscopic observation of mu-opioid receptor in the rat area postrema. Peptides, 20, 873-880. doi:10.1016/S0196-9781(99)00075-3

[61] Snyder, S.H. and Pasternak, G.W. (2003) Historical review: Opioid receptors. Trends in Pharmacological Sciences, 24, 198-205. doi:10.1016/S0165-6147(03)00066-X
[62] Bhandari, P., Bingham, S. and Andrews, P.L. (1992) The neuropharmacology of loperamide-induced emesis in the ferret: The role of the area postrema, vagus, opiate and 5- $\mathrm{HT}_{3}$ receptors. Neuropharmacology, 31, 735-742. doi:10.1016/0028-3908(92)90034-M

[63] Mosqueda-Garcia, R., Inagami, T., Appalsamy, M., Sugiura, M. and Robertson, R.M. (1993) Endothelin as a neuropeptide. Cardiovascular effects in the brainstem of normotensive rats. Circulation Research, 72, 20-35. doi:10.1161/01.RES.72.1.20

[64] Fregoneze, J.B. and Antunes-Rodrigues, J. (1992) Role of opioid peptides and subfornical organ in the renal function of intact and hypophysectomized rats. Physiology and Behavior, 51, 287-292. doi:10.1016/0031-9384(92)90142-O

[65] Gatti, P.J., Dias Souza, J., Taveira Da Silva, A.M., Quest, J.A. and Gillis, R.A. (1985) Chemical stimulation of the area postrema induces cardiorespiratory changes in the cat. Brain Research, 346, 115-123. doi:10.1016/0006-8993(85)91100-X

[66] Ferguson, A.V., Beckmann, L.M. and Fisher, J.T. (1989) Effects of subfornical organ stimulation on respiration in the anesthetized rat. Canadian Journal of Physiology and Pharmacology, 67, 1097-1101. doi:10.1139/y89-173

[67] Bodineau, L. and Larnicol, N. (2001) Brainstem and hypothalamic areas activated by tissue hypoxia: Fos-like immunoreactivity induced by carbon monoxide inhalation in the rat. Neuroscience, 108, 643-653. doi:10.1016/S0306-4522(01)00442-0

[68] Sarton, E., Teppema, L. and Dahan, A. (1999) Sex differences in morphine-induced ventilatory depression reside within the peripheral chemoreflex loop. Anesthesiology, 90, 1329-1338. doi:10.1097/00000542-199905000-00017 